\title{
The Place of Symbols in African Philosophy
}

\author{
Bonachristus Umeogu \\ Department of Philosophy, Faculty of Arts, Nnamdi Azikiwe University, Awka, Nigeria \\ Email: ojiakor99@yahoo.com
}

Received August $6^{\text {th }}$, 2012; revised September 10 ${ }^{\text {th }}$, 2012; accepted September $24^{\text {th }}, 2012$

\begin{abstract}
Communication cannot do without symbols. There always comes a time when one runs out of words and symbols step in where words have failed. Civilization has changed many aspects of people's culture, beliefs and actions. In African philosophy and within the African culture, this paper tries to mirror the place of symbols within African philosophy.
\end{abstract}

Keywords: African Philosophy; Symbols; Communication Symbolism

\section{Introduction}

Way before communication as we now know it was conceptualized and contextualized, man has always communicated with symbols. This means that from time immemorial, symbols have played a communicative and interactive role to man in general and, Africans in particular. Even the developed countries did not spring into giants overnight. History will reveal that their ancestors must have had their own way of communication. In other words, communication has evolved overtime to what and where it is today.

Dukor in one of his works on African philosophy observed that symbols are natural to man way before formal languages. In other words, senses can only work when there are symbols. By implication, symbols are everywhere, some we understand and others we are not even aware of, not to mention understanding its meaning or the message behind them.

The fact remains that symbols in most occasions start where words have stopped. They are used to delve and signify meanings that defy the constructive use of words. This paper primarily looks at African philosophy as a whole and the place that symbols occupy in the African philosophy. It will also identify the challenges of African philosophy and expatiate on some African symbols and their symbolisms.

\section{What Is Meant by African Philosophy?}

Philosophy literally means the love of wisdom; an unquenchable thirst to find answers to unending questions and meanings; the insatiable desire to probe and understand the reasons for things, events and even nature; an obsession to be in the know at all times.

Ukagba (2000: p. 80) observed that "when an African or indeed a non-African philosopher writes or reflects about African wisdom, the Africa world view, the African existential identity, or African ideologies, he does African philosophy". As this paper is trying to reflect on the place of symbols within the African culture, it is African philosophy in practice. By way of definition, Iroegbu in Ukagba (2000: p. 78) saw African philosophy as the "reflective inquiry into the marvels and problematica that confront one in the Africa world view, in view of producing systematic explanation and sustained responses to them”.

This demonstrates that African philosophy is more practical than theoretical. It is its practicability that will ensure its arrival and sustenance on the same pedestal as continental philosophies. At this point, the question that will be on the minds of many, especially western philosophers is; when did African philosophy become part of the big family of philosophy?

Before I delve into defense of African philosophy, I want to make an observation/assertion that if philosophy is big enough to accommodate Continental, American, Indian or Chinese philosophies, then there ought to be room for African philosophy. Be that as it may, the problem is not with philosophy accommodating African philosophy but Western and even African philosophers accepting African philosophy to claim their rightful place on the same pedestal as Western philosophies.

For there to be philosophy, there must be a kind of reflections and organization; a kind of rational appreciation, constitution and control of the meaning of things. So in Africa, if there are such things like aspects of culture, tradition, thoughts that have been subjected to that kind of level of analytic, rational and intellectual scrutiny, that can pass as philosophy. That is why it is argued that without the analytic prodding, probing and scrutiny, there won't be any room for whatever will be called philosophy. And if there is no philosophy, African philosophy would be a mirage.

No matter how it is viewed, every philosophy is a cultural philosophy. Here, cultural is used in the sense that it bothers on the realities, traditions and thoughts of a particular society. Culture varies from society to society in that despite the promises of globalization to unite cultures, there are significant differences in cultures. This necessitated the different types of philosophies namely: American, Chinese, Continental, Indian and recently, African philosophy.

Commenting on the reason for its newness is Ukagba (2000: 76) who submitted that

African philosophy within the context of conceptualization and intellectualization is a recent phenomenon in our institutions of higher learning. It is a recent phenomenon not because the Africans have not been cultivating philosophy since time immemorial but because as an academic enterprise, like many other disciplines, it has been denied the Africans or black race all over the world.

What makes a cultural philosophy to be recognized and ac- 
cepted as philosophy? One of the tenets of philosophy is that it must be rational, scientific, systematic, consistent, coherent and organized. Also, it has been said that philosophy has to be universal. If it is on this ground that the legality and acceptability of African philosophy is being contested, I wonder why there was room for other types of philosophy. There would not have been any need for American or Chinese philosophy. If the two are same for instance, the need for classification would not have been raised. American philosophy should have also applied to Indian philosophy and vice versa. One might be tempted to question what really philosophy is, because philosophers as regards what philosophy is, does not mean what it says.

On rationality as a basis, man is man despite their skin pigmentation. The fact that Africans are black does not make them less a man or less a human being. If man is a rational being and an African is a man, then he must have rational thoughts. The fact that he has rational thoughts means that he can philosophize and whatever he philosophizes is rational enough to be called African philosophy. It is as simple a logic as that.

The reality is that rich or poor; black or white; master or servant; developed or under-developed, we all philosophize whether it is conscious or not. Philosophizing in this context means to inquire; to probe; to question; to understand; to explain; and the capability to give answers or clarify issues that border on understanding and compartmentalizing events and happenings within a specific cultural setting. On this, Maduka (2000: p. 3) has this to contribute:

Philosophizing is part of what it means to be human. True enough, we may differ in our levels of philosophizing (some reflect more deeply, profoundly, systematically and rigorously than others; some consciously and explicitly proffer reasons for what they do, others conjure their reasons in retrospect while in fact some others are not aware of their reasons and principles at the point of action) but we all philosophize all the same in some degree or other.

On the ground of African philosophy being scientific, science is all about being organized and proven. Omenzejele (2000: p. 57) observes that the foremost characteristics of science are that it should be specific, public, impersonal and objective". Well, there would never have been talk of African philosophy if it has not been constituted and reorganized and these can be and was done through rational scrutiny; intellectual scrutiny; analytic appreciation and reorganization of a reality either cultural or otherwise.

\section{African Philosophy on Symbols}

"Every knowledge, every meaning of existence must almost all of the time, involve some kind of reasoning with symbols, in symbols, by symbols and through symbols”. This was submitted by Umeogu (2012) who tried to explain the highly revered place of symbols within the African philosophy. Dukor (2010: p. 200) asserted that "the evolution of human mind was accompanied simultaneously with the evolution of symbols and concepts" and that "Man's understanding of the world, himself and the environment is characterized and associated with symbols”. What are symbols and how do we know them before we will understand its place in African philosophy?

On how to identify symbols, Firth in Dukor (2010: p. 200) is of the view that "symbols as instrumental tools in any cultural set-up are characterized by their expressive, communicative, cognitive and regulative qualities".

In his own way, Umeogu (1996: p. 75) documents that

... the symbol is something; but it's something for something; that is, something that stands with something, for something and to something. The symbol begins from something and ends towards something for which it is the symbol. As such, it provides food for thought as well as thought for food. As it signals, signs and flows what it is beyond and to what it shows...

Dukor (2010: p. 200) while noting that symbols could be grammatical, technical, logical or mystical saw symbols in a general sense as that, which expresses, represents, stands for, reveals, indicates or makes known another reality.

At this juncture, I want to ask if signs and symbols are same or different. This question came as a result of a statement by Dukor that "symbols could pass as sign but not all signs are symbols". By way of functionality, symbol is different from sign because symbol is always different from what it represents. In other words, symbol is always of a representative importance. The philosophy of symbolism is a philosophy of representative importance as regards communicative functions. Symbols, representation and communication are all interlinked in that there cannot be one without the other. The power of symbols is gotten from its ability to represent something that can effectively communicate its meaning to the receiver. Also, can there be communication without representation? For there to be an effective communication, there has to be a representation that is in consonance with the receivers reservoir of knowledge be it a signal, a sign, a symbol or even a word. When a receiver does not understand the representative meaning of a symbol, communication cannot be said to have taken place. This is what the philosophy of representative importance as regards communicative functions are all about.

Be that as it may, what sign signifies can be discerned by seeing it. For instance, smoking is the sign of fire because the two go together so much so that there is a saying that "there is no smoke without fire”. An instance of symbol is green, white and green. This colour symbolizes Nigeria but there is no way you can link the colour to Nigeria as explicitly as that of smoke and fire. Symbols are just like that. They (symbols) do not give that kind of obvious meanings in that they are mostly or always different from what it signifies.

Paul Ricoeur, a French philosopher, once said that a symbol gives food for thought. In other words, symbols do not have a complete meaning. They have the tendency of making one to look beyond the ordinary; to exercise the audience's mental energy in trying to figure out the man behind the mask. One can also say that symbols carry meaning over: it allows people to read and see meaning that is hidden or implied.

Every symbol has an implicit meaning. Implicit here means that what is said is in an enigma. Enigma in the sense that it is shrouded in camouflage; not a direct expression but rather has an indirect impression. Such an impression should be expressed; and expression of such impressive meaning is what is called symbolism. This demonstrates that every symbol is incomplete. The full appreciative explication becomes the fullness of meanings in the symbols.

Coming to signs, signs are what they are. In other words, they are not open to interpretation; rather, they always have a 
fixed and precise meaning. An instance was given by Stenger who used the traffic signs as an instance whereby when the traffic light is red, it means that you must stop until it changes to green. A sign needs to be precise and unmistakable.

In the light of the above as it relates to symbols, one can understand its importance to Africans as a whole. Commenting on the general importance of symbol and its power in African culture is Stenger who submitted that "A symbol opens the door into a larger world. It goes beyond what is visible and tangible. It opens the door especially to the world of mystery". He went on to explain the importance of symbols in the quote below:

... because symbols can say more than words. In this sense, a symbol is a powerful instrument to extend our vision, to stimulate our imagination and to deepen our understanding. Without symbols, we are unable to arrive at the truth. Words alone cannot express the whole reality. People in the Western world who are influenced by an unconscious materialism, often equate reality with physical, measurable reality, whereas Africans can often see the symbolic meaning of things and events, because they are convinced that reality is more than what can be seen and measured. They are often able to see a symbolic or spiritual meaning in events like sickness, death and disasters...

\section{Types of Symbols}

Onwubiko in Dukor (2010: p. 201) identified three types of symbols namely; direct symbol, indirect and non-material symbol. Direct symbols are symbols whose material image expresses what they mean ideologically. Indirect symbols represent symbols whose material objects signify a different thing which is not immediately discerned in the material. Finally, there are non-material symbols, which are expressed in gesticulations and linguistics symbols which are forms of expression in which the actual meaning of the signs is known through an in-depth reflection. One would have expected Dukor to give instances or examples of the different types of symbols so that philosophers and non philosophers alike will have a good ground to understand, agree or disagree with the classification.

Here, I want to categorically state that no matter the types of symbols, its functionality and translatability is culture specific. It is culture specific in the sense that it will function as a symbol within a particular cultural setting or to a sect of people. For instance, cross is sacred to Christians but other religions do not hold it in such high esteem. An occult symbol will look like a drawing to a non-member while it is the summary of their faith to a member.

At this juncture, let me list some symbols whose meanings may or may not be culture specific in Africa.

- Mmiri: purity, life etc.

- Oji: acceptance, unity of life, love etc.

- Ose oji: vibrator, seasoner, activator etc.

- Nzu: purity of heart, gift of love for all etc.

- Ofo: truth and justice.

The Ofo as it is called in the Igbo African society is a piece of wood that is a symbol that signifies justice. According to Umeogu (1996), ofo has no general meaning as ofo ozo symbolizes the sceptre and truth of the kingly-spirit in force of it and is used by the holder to attest to the gravity, truthfulness and innocence of the title he holds and, to discharge his office in relation to it. On the other hand, ofo-ana represents the power and presence of the earth goddess and is used to care and remove abominations from the lands.

Well, by saying that ofo for instance has no general meaning may imply that symbols do not have a universal meaning. What it shows in essence is that the claim that symbols are quite different from what it represents is not unfounded. It also goes to prove that they speak in an enigma in that the meanings are always wrapped in camouflage.

- Mmanya: spice of life, spirit of health etc.

- Cross: sanctuary, death, danger etc.

- Flower: appreciation, love, romance, condolence etc.

Symbols are often used when words are unable to express complex realities: a deep feeling of love for a person may be expressed by giving that person a red rose, Stenger

(http://www.karibu-stenger.net). There are flowers for different occasions where words are unnecessary. For instance, the flower called bleeding hearts is used as a sign of condolence.

\section{The Philosophy of Symbols and Representation}

The philosophy of symbolism bothers much on what can be called representative philosophy. Representative in the sense that it represents a people; represents words; represents action; and represents thoughts because there is no way a persons' thought can be carried out. Every philosophizing works on that and if that "working" is systematic, rational and analytic, that is philosophy. There is always that super-personal angle of what is represented. In other words, every thinker thinks about something. The object of thought and the subject of thought are not the same. At the end of the day, every philosophy is representative. Symbols point beyond itself and in most cases bear no resemblance to its signified. This shows that symbols are all about representation.

The idea of symbols of representation in philosophy can be attributed to Ernst Cassirer who was a philosopher of symbolism. In Cassirer's vision, scientific laws, religion, and language are all symbols created by the mind in attempting to produce a world of understanding. The philosophy of symbols is the philosophy of something. In fact, the power of symbols is gotten from its power of representation at any point in time. Symbols are called symbols as a result of the power of representation. In most occasions, it plays a mediatory role symbols between man's perception and subsequent understanding. In essence, it activates the power of a rational being to assimilate information and to compartmentalize and construct them to fit into certain symbolic referents which enable the receiver to understand the world. Symbols represent knowledge. Knowledge is made explicit through symbols.

Commenting on symbols and meaning, Luft (2005) submitted that in the "world of meaning-and there is no other real world for us-there is not merely one perceived $\mathrm{X}$ as a substratum with different meanings, but what this $\mathrm{X}$ is understood as depends on the symbolic form within which it is viewed, i.e., thematized". Cassirer in Luft (2005) calls these forms symbolic because the " $\mathrm{X}$ " in view is never a simple substance but stands as a symbol for the form in which it has its function. It points to the meaningful whole or totality: to the world of myth, of art, of religion, of science.

The final word on the philosophy of symbols is that, the logic of symbolism is the logic of representation. Thought is about something and between the thought and something, comes in the representation of symbols to bring about or bring 
out the representative meaning.

\section{Challenges Facing African Philosophy}

Ukagba (2000: p. 91) observed that language is one of the difficulties in the study of African philosophy. According to him, language is the soul of a culture, the heart of an environment ... Language constitutes an indispensable tool in the process of cognition and is one of the epiphanies of human rationality. African thought in a foreign language is not fully African thought. African philosophy done in a foreign language is not yet African philosophy". If that is the case, there are many African languages as there are African countries. In such a scenario, which language becomes the official language? It was easy for Western philosophers since English is their lingua franca. In that case, symbols should step in to take Africans to the promised land of philosophical recognition and universal acceptance. A similar view is expressed in the following words:

The subject of philosophy, literate or preliterate is an open book which each group or society reads and interprets in its own "verba" or concepts ... the African would not cease to be a philosopher even in the formal sense of the word if at some stage, he abandons the use of the expression in European language and reverts to its native language. (Nze 2009 in Umeogu 2012).

Secondly, it is being challenged by what I call academic racism. Umeogu (1996: p. 156) notes that the popular illusion is that the African scholarship ability cannot both be good and original. Where it is original, it is not good, where it is good, it is not original. Consequently, the "tumulting nations and the 'murmurous people of the earth' concluded, that never can there be anything like African philosophy...”

There is another factor that I refer to as internal problem. Philosophy and philosophers have a problem in that there is really no universally accepted parameter of what constitutes philosophy. This gave rise to empiricism, rationalism, pansychism and what have you. This problem is heightened by each seeing itself as the only true form of philosophy. An observation was made to that effect by Isiguzo (2000: p. 43) that "philosophy is burdened by fundamental problems. The problem includes that of ... conceptualization which cannot be solved in a dogmatic manner as in religion or, by way of laboratory experiment as in science. Philosophical questions are not answered dogmatically or empirically".

\section{Conclusion}

Shakespeare once observed that some are born great, others achieve greatness, while some have greatness entrusted on them ... this is the case with philosophy. Some are seen as philosophy without passing the rationality test while others have to pass hurdles to be seen fit to have the name philosophy attached to them. In this case, African philosophy belongs to the class that will have to achieve greatness.

The philosophy of symbols is a kind of hermeneutics interpretation. It kind of interprets the meaning of a symbol by considering what that symbol signifies. Hermeneutics here simply means to make what is implicit become explicit. So, whether African philosophy is universally accepted or not, the fact remains that symbols have come to stay as far as African philosophy is concerned. Little wonder why Dukor rightly asserted that symbols pervade the African life and give meaning to their communal existence. If symbols truly make for unity in various aspects of African beliefs and existence, then one can now understand the highly revered place of symbols to the Africans. By nature, Africans are communalistic in orientation and if symbols tighten that bond, then it is going nowhere.

\section{REFERENCES}

Dukor, M. (2010). African philosophy in the global village. Saarbrücken: Lambert Academic Publishing.

Isiguzo, A. (2000). Problems of philosophy. In C. Maduka (Ed.), Philosophy and logic: A primer (pp. 43-56). Benin: Department of History.

Luft, S. (2005). Cassirer's philosophy of symbolic forms: Between reason and relativism; a critical appraisal. Idealistic Studies, 34.

Maduka, C. (2000). Nature, scope and relevance of philosophy. In C. Maduka (Ed.), Philosophy and logic: A primer (pp. 1-19). Benin: Department of History.

Omenzejele, P (2000). Philosophy as a second order discipline. In C. Maduka (Ed.), Philosophy and logic: A primer (pp. 57-75). Benin: Department of History.

Stenger, F. (2012). The power of symbols in African culture. http://www.karibu-stenger.net/en/articles/power_of_symbols.shtml

Ukagba, G. (2000). What is African philosophy. In C. Maduka (Ed.), Philosophy and logic: A primer (pp. 76-98). Benin: Department of History.

Umeogu, B. (1996). Principia logica. Onitsha: Mid-Field Publishers.

Umeogu, B. (2012). Symbolic universe: Towards a New Universe of Knowledge, a new Logic and a new African Philosophy. Enugu: Victojo Press.

http://ai.eecs.umich.edu/cogarch0/common/theory/symbol.html 